\title{
REVISIÓN DEL PROCESO CONTRA EL DERECHO NATURAL*
}

En 1954, el profesor A. P. d'Entreves pronunció una serie de conferencias en la Escuela de Derecho de Notre Dame, que fueron publicadas más tarde bajo el título de "Nuevo examen del proceso en favor del Derecho Natural".1 En estas conferencias, como indica su título, los argumentos en favor del uso del concepto de derecho natural en la discusión y solución de problemas de filosofía jurídica, fueron desarrollados por el profesor d'Entreves en forma afirmativa, aunque en el curso de su exposición también recurrió a veces al método negativo de refutar diversas teorias opuestas a sus creencias fundamentales. El presente artículo -como se muestra de nuevo por el título-, utiliza un camino de acceso un poco diferente. La discusión se centrará en torno a algunas teorías de mucha influencia, que fueron propuestas con el fin de impugnar la validez de la doctrina del derecho natural, y que obtuvieron éxito en la tarea de lograr considerable apoyo en favor de los críticos de dicha doctrina.

Los puntos de partida para la discusión serán proporcionados por la escuela ideológica opuesta al derecho natural. No se tiene la ambición de presentar y valorizar en forma completa las opiniones de los pensadores opuestos al derecho natural. La literatura sobre el tema es amplia y muy dispersa, y sería necesario un libro de varios tomos para tratar este campo en forma comprensiva y exhaustiva. El presente ensayo se limitará a unas pocas teorias que parecen haber llevado un peso muy importante en la disputa. $^{2}$

El tema del derecho natural se ha puesto muy de moda en nuestros días entre los eruditos del derecho y los sociólogos, y ha provocado muchos debates en la literatura jurídica y no jurídica del mundo occidental. Este renovado interés por el problema del derecho natural no se extiende más allá de los días de la segunda Guerra Mundial. ${ }^{3}$ Antes de ese tiempo, y

- J. U. D., Universidad de Heidelberg, 1932; LL. B.; Universidad de Washington, 1937; Catedrático de Derecho, Universidad de Utah.

Este artículo es una versión revisada y ampliada de una conferencia pronunciada ante los estudiantes de derecho de la UNAM, el 17 de septiembre de 1969 .

1 D'Entreves, "The Case for Natural Law Re-examined", I Natural L. F. 5 (1956).

2 Otros argumentos en relación con la disputa, aqui omitidos, se discuten en Bodenheimer, "The Natural-Law Doctrine before the Tribunal of Science: A Reply to Hans Kelsen", 3 West. Pol. Q. 335 (1950).

$3 \mathrm{El}$ pensamiento iusnaturalista ha sido siempre divulgado en la literatura neoto. 182 
especialmente en la primera parte del siglo $\mathrm{xx}$, el derecho natural parecia haber casi desaparecido de la escena, $o$ cuando menos haber sido en su mayor parte relegado al museo de antiguiedades históricas. El jurista alemán Karl Bergbohm, quien consideró como la misión de su vida erradicar los últimos vestigios del pensamiento iusnaturalista donde quiera que los encontrara, estaba seguro de haber obtenido éxito en su empeño, y hubo seguramente muchos testimonios válidos en su época para probarle que su opinión era justificada. Especialmente en Alemania, un erudito en el derecho, sospechoso de simpatizar con el iusnaturalismo, sencillamente no era considerado como un miembro respetable de la comunidad académica, y los esfuerzos para propagar esa doctrina desde las cátedras de las universidades alemanas, habrían encontrado mucha oposición y desaliento en aquel periodo.4

¿Cuáles eran las objeciones suscitadas por Bergbohm y sus discípulos contra la doctrina del derecho natural? ${ }^{5}$ La crítica principal era que el iusnaturalismo, en sus manifestaciones de mayor influencia históricamente, descansaba en la hipótesis de preceptos permanentes, fijos, más o menos universales, que podían reclamar validez para todos los sistemas éticos y órdenes jurídicos. Los críticos afirmaban que semejantes preceptos universales no existían, que era una ficción de la pura fantasía. En apoyo de este argumento señalaban la diversidad y heterogeneidad de la regulación normativa en los diversos países del mundo. Lo que es considerado como delito en el Estado A, es visto como perfectamente lícito en el Estado B. Lo que parece ser un contrato perfectamente válido y ejecutable en un país, es prohibido como contrario al orden público o a los bonos mores en otro. Una práctica comercial proscrita como censurable en algunas comunidades, es aceptada como inobjetable en otras. Una forma de difamación punible en algunos ordenamientos jurídicos, puede, en otros, estar exenta de "castigo. Esta era la fuerza principal de la argumentación.

Debería señalarse que la confianza en la evidencia empírica de una diversidad cultural y legal no destroza, per se, y sin trazos adicionales de argumentación, los posibles fundamentos de un enfoque iusnaturalista. La réplica que el jurista del.derecho natural pudiera ofrecer en refutación, podría desarrollarse como sigue: aun cuando tenga que concederse que los sistemas jurídicos y éticos son diversos e inconsistentes, esto no prueba que un sis-

mista sobre el derecho y el Estado. El rasgo caracieristico del desarrollo desde la segunda Guerra Mundial ha sido la rápida extensión del interés por este tema hacia círculos notomistas.

4 El que una actitud semejante haya prevalecido en las facultades norteamericanas de derecho en los años veinte de este siglo fue señalado por Kats, "Natural Law and Human Nature", 3 U. Ohio Law School Rec. 1 (1954).

5 Véase particularmente Bergbohm, Jurisprudenz und Rechtsphilosophie, 175 y sigs, 425 y sigs. (1892). 
tema jurídico o ético no pueda ser superior a otro $y$, por lo tanto, mejor adaptado al cumplimiento de los fines básicos de la organización política y social. La doctrina del derecho natural nunca ha pretendido que sus postulados básicos sean universales en el sentido de que no puedan ser infringidos por un orden jurídico empírico. Así, es enteramente posible que el orden jurídico del Estado $\mathbf{A}$ se halle en conformidad con el derecho natural, mientras que el del Estado B lo viole. Si éste fuera el caso -así continuaría la argumentación - hay muchas razones para creer que el orden jurídico del Estado B, por no ser muy consciente de ciertos rasgos indestructibles de la naturaleza humana, o por no corresponder a ellos, sufrirá crisis, derrumbamientos y eventualmente desintegración, a menos que sea adaptado a las necesidades existenciales de los seres humanos.

El positivista jurídico estaría inclinado a enfrentarse a esta aserción, poniendo en duda la disponibilidad de algún criterio científico por el cual el orden jurídico de un país pudiera ser juzgado superior al de otro. Sostendría que los criterios de lo justo e injusto son condicionados y formados por convenciones y modelos de valor de una cultura particular, y que ninguna sociedad tiene el derecho de condenar o criticar el sistema ético y jurídico de otra sociedad, sobre la base de que sus conceptos del bien y el mal son defectuosos o inadecuados. Si se dejan oír tales críticas, argüiría el positivista jurídico, éstas no representan más que reacciones subjetivas e irracionales de individuos o grupos particulares, y tendremos que juzgarlas como desprovistas de validez objetiva y justificación racional. En esta refutación de la posición iusnaturalista va implícita la hipótesis de que no existen necesidades de los seres humanos que exijan reconocimiento absoluto por todos los órdenes juridicos, $\cdot y$ de que la naturaleza humana es suficientemente viable e indeterminada para prestarse a experimentos más o menos ilimitados de acondicionamiento cultural y reajuste social.

Ya que los méritos de las posiciones antagónicas sobre la cuestión del derecho a valorizar sistemas sociales dependen en grado considerable de la verdad o falsedad de la doctrina de la relatividad ética, parece necesario regresar al punto principal de la crítica de Bergbohm al pensamiento iusnaturalista. En los tiempos en que Bergbohm propagaba sus puntos de vista, la opinión meditada de la mayoría de los sociólogos y antropólogos era que no existían valores sociales o morales que fuesen reconocidos en todas partes o pudiesen reclamar validez absoluta. Pero desde el comienzo del siglo xx se hicieron muchos adelantos en sociología y antropología cultural, y a la luz de los nuevos hallazgos la doctrina de la relatividad ética y jurídica ha perdido gran parte de su fuerza. Sabemos actualmente que existen muchas uniformidades y congruencias en los sistemas morales y jurídicos de todos los pueblos, cuando menos de todos aquellos que han superado la fase más 
cruda y primitiva de su evolución. ${ }^{B}$ Así, se ha descubierto que la matanza indiscriminada de los miembros de algún grupo social es prohibida en todas partes; que algunas de las manifestaciones más groseras de la conducta antisocial, como el rapto, el asalto y la rapiña son proscritas universalmente; que ciertos requisitos elementales de buena fe en el trato reciproco de los hombres son siempre impuestos a los miembros de las sociedades; y que la propiedad privada de ciertos artículos de uso personal, como instrumentos y ropa, encuentra un reconocimiento casi universal. A medida que las sociedades progresan hacia formas superiores de desarrollo, tiende a aumentar el número de principios comunes que se consideran indispensables para un ordenamiento adecuado de los negocios humanos. ${ }^{7}$ Así, en sociedades civilizadas se considera esencial para un desempeño apropiado del procedimiento judicial, que no se condene a nadie sin que haya pruebas en apoyo de la acusación; que el juez no conozca las pruebas aducidas si están afectadas por perjuicio o falsedad y que los procesos no sean decididos a base de sobornos ofrecidos al juez. ${ }^{8}$

Si existen modelos éticos universales, aun cuando queden limitados a unos pocos principios generales y básicos, y si estos modelos dieron origen a formas congruentes de regulación jurídica, es altamente inverosímil que este fenómeno sea el resultado de circunstancias accidentales. Hay un alto grado de probabilidad, casi una seguridad, de que estas uniformidades culturales tengan sus raíces en lo que se puede llamar "la naturaleza común del hombre". Es verdad que hoy en dia encontramos alusiones, dispersas en la literatura existencialista, a la conclusión de que no existe algo que pueda llamarse naturaleza común del hombre, y que propiamente sólo podemos hablar de la naturaleza o carácter de un individuo particular. ${ }^{9}$ Este punto de vista no puede ser aceptado. Las ciencias de la psicología y psiquiatría serían imposibles si los hombres no reaccionaran en una forma general frente a los hechos y experiencias de la vida, y frente a la conducta de sus semejantes. El psicoanálisis, por ejemplo, nos ha enseñado que ciertas formas de experiencias infantiles producen resultados típicos, que muchas veces pueden ser evitados mediante actitudes prácticas y correctas por

6 Para referencias de bibliografía y una breve relación del cstado actual de la doctrina, véase Bodenheimer: Jurisprudence: The Philosophy and Method of the Law, 188190 (1962). Véase también Hart, The Concept of Law, 189-195 (1961).

7 Este elemento dinámico del derecho natural explica tal vez la siguiente aseveración de Aristóteles, que ha desconcertado a muchos intérpretes: "En nuestro mundo, aunque existe algo semejante a una justicia natural, todas las normas de justicia son variables... Es fácil ver cuáles normas de justicia, aunque no absolutas, son naturales, y cuáles no son naturales, legales y convencionales, siendo ambas clases a la vez variables." Aristóteles, Etica Nicomaquea, Libro $\mathrm{V}$, vii.

8 Hay países donde se ha extendido la corrupción judicial, pero el hecho de que los casos de corrupción sean escondidos a la vista del público, muestrá que la opinión pública prevaleciente considera tales prácticas como perversiones de la función judicial.

9 Véase, por ejemplo, Sartre, Existentialism, 27 (1947). 
parte de los padres, y que existen manifestaciones de un comportamiento neurótico o psicótico que surgen de factores más objetivos en su carácter que los rasgos característicos altamente individualizados de una persona particular. En otras palabras, causas similares producen frecuentemente reacciones o perturbaciones psicológicos similares, y esto tiene que deberse necesariamente a ciertas uniformidades en la naturaleza humana. En realidad, los hombres no podrían tratar ni comunicarse con otros, en forma inteligente y con éxito, si cada individuo fuese completamente y en todo respecto diverso de cualquier otro individuo. Existen, afortunadamente, muchas diferencias individuales entre los hombres, pero también los hombres tienen cierta parte de su physis y psyché en común con otros. ${ }^{10}$

Esta conclusión, sin embargo, no resuelve el problema al cual se dirige nuestra discusión. Si podemos suponer que existe una naturaleza humana común, a la que se superponen las diferencias individuales, y que esta naturaleza común es responsable de importantes identidades y similitudes entre los sistemas jurídicos del mundo, esto no apoya ni justifica, sin un eslabón más en la argumentación, la tesis del iusnaturalista. En el mundo del derecho nos ocupamos mucho más en el problema del "deber ser" normativo, que en el reino ontológico del "es". Es verdad que las prescripciones normativas fijadas por el derecho quedarán a menudo sin efecto, a menos que estén seguramente ancladas en los hechos de la realidad empírica, la cual impone limitaciones a los poderes y vuelos de la fantasía de los legisladores. Pero esto no significa que no existan en gran escala tensiones y discrepancias entre lo que es y lo que debe ser. ¿No estamos en peligro de bloquear caminos de progreso social si establecemos conclusiones firmes en cuanto a los rasgos fijos e invariables de la naturaleza humana y si declaramos que tales rasgos constituyen barreras insuperables para experimentar con la condición humana mediante el derecho positivo? El hecho de que hasta ahora hayamos observado en los sistemas jurídicos de este planeta ciertos ingredientes comunes, ¿ofrece alguna prueba de la afirmación de que estas normas comunes deben ser reconocidas, preservadas y perpetuadas como limitaciones eternas a los esfuerzos de mejoramiento humano por medio del instrumental del derecho positivo?

A primera vista, este argumento contra la posición iusnaturalista parece tener una amplia fuerza persuasiva. Por ejemplo, muchos filosofos y psicólogos han afirmado que existe un componente fuerte e irreprimible de egoísmo y autoafirmación en la naturaleza humana. El sociólogo Herbert Spencer, por otra parte, creía que mediante un proceso estrictamente determinado de evolución hacia formas superiores y más refinadas de civilización,

10 Véase Verdross, Abendlaendische Rechtsphilosophie, 244 y sigs., $268 \quad$ (2 $^{\mathrm{a}}$ ed., $19^{6} \mathrm{~g}$ ). Sobre la filosofía del derecho de Verdross, véase Kunz, "La Filosofía del Derecho de Alfred Verdross", Diánoia, 1962, 209. 
los hombres perderian mucho de su actual egoísmo y adelantaría el aspecto altruista y cooperativo de su naturaleza. ${ }^{11}$ Esta convicción fue su principal arma contra el cargo de que su defensa de una libertad ilimitada y del laissez-faire produciría fácilmente la anarquía y el predominio de prácticas depredatorias en la vida social. Muchos sociólogos rechazarian hoy la creencia de Spencer de que la humanidad fue forzada por leyes inevitables y mecánicas de desarrollo a dirigirse hacia una fase de interadaptación social y armonía de intereses. Pero esto no elimina el problema de si debería hacerse o no una tentativa consciente y deliberada a través de la legislación, la educación y otros medios, para fortalecer el componente social de la naturaleza del hombre. Si alguna teoría iusnaturalista desalentase los tales empeños encaminados a mejorar las actitudes cooperativas en los seres humanos, sin duda alguna se expondría a la acusación de ponerse en el camino del progreso humano.

La réplica a esta objeción debe ser que ninguna de las teorías iusnaturalistas que han jugado un papel importante en la historia de la teoria juridica, ha puesto obstáculos de esta índole en el camino del progreso social. Aun cuando todas estas teorías han reconocido algunas limitaciones intrínseca a los poderes de los legisladores, derivadas de la realidad de la naturaleza humana, ninguna de ellas ha declarado que los esfuerzos para hacer a los hombres más cooperativos y más inclinados a lo social, fuesen contrarios al derecho natural $\mathrm{y}$, por lo tanto, estuviesen destinados a terminar en el fracaso. Al contrario, la gran mayoría de los filósofos iusnaturalistas partieron del supuesto de un instinto social en el hombre, a cuyo perfeccionamiento y tutela está destinada la institución del derecho. Inclusive Thomas Hobbes, que se inclinaba a acentuar más fuertemente que ningún otro filósofo del derecho natural, los impulsos egoístas, no cooperativos y agresivos del hombre recomendaba un correctivo a esta defectuosa condición de la naturaleza humana mediante la creación de gobiernos con brazo fuerte, capaces de imponer la obediencia a la regla de oro, y el mantenimiento de un respeto mutuo para los derechos privados, especialmente para los derechos contractuales y de propiedad. ${ }^{12}$ En otras palabras, la función del Leviatán de Hobbes debía ser educar a seres humanos que, en estado de naturaleza, se comportarían entre así como lobos rapaces, a fin de que se condujeran como ciudadanos decentes y permitieran a sus semejantes vivir una existencia pacifica y exenta de perturbaciones.

Lo que la doctrina iusnaturalista ha afirmado siempre, es que los instintos destructivos del hombre deben ser mantenidos bajo control, y que hacen falta frenos contra la violencia y la indiscriminada inflicción de daño, en bien de la organización y preservación de los grupos sociales. El mandato

11 Spencer, Principles of Ethics, 204/5, 215-218 (1898); Spencer, Justice, 31/2, (1891). 12 Hobbes, De Cive, Ch. XIII (ed. Lamprecht, 1949). 
de no perjudicar a otros miembros de una sociedad ha sido, con ciertas limitaciones y excepciones, una de las bases principales del pensamiento iusnaturalista. Sin embargo, debe concederse que este mandato no ha sido reconocido plenamente en lo que concierne a las relaciones entre un grupo social y los considerados por éste como enemigos externos o internos. Esto no prueba la incorrección del juicio de que es una meta fundamental del derecho refrenar la agresión humana; sólo demuestra que ahí donde los seres humanos inician una campaña de violencia y exterminio usualmente no es el derecho el que les sirve de guía para la acción en tales casos. Inter armas leges silent. Es digno de notar que donde el derecho ha emprendido la tarea de reglamentar la guerra, el objetivo ha sido, en la mayoría de los casos, un intento de reducir las prácticas inhumanas en combate o en el tratamiento de los prisioneros, más bien que multiplicar los horrores de la lucha.

Estas afirmaciones no pretenden implicar que el derecho no haya sido utilizado, en algunas situaciones históricas, como instrumento para la hostilización, opresión o aun extinción de grupos. Pero precisamente contra estos tipos de derecho la doctrina iusnaturalista ha levantado la voz de su crítica, suscitando la cuestión de su fuerza obligatoria.

Si las observaciones antecedentes son verdaderas, el problema que dio origen a esta discusión puede estar dentro de la mira de una solución aceptable. El problema era si una teoría iusnaturalista, basada en el "es" ontológico de convicciones éticas congruentes y elementos comunes en los sistemas jurídicos, no puede olvidarse de la deseabilidad de cambiar el "es" ontológico, por intentos normativos, con el fin de mejorar la condición humana. La contestación que hemos propuesto ha sido que aquellos elementos de los sistemas jurídicos que, en el lenguaje de Aristóteles, tienen "en todas partes la misma validez", ${ }^{13}$ consisten esencialmente en restricciones formadas dentro del grupo contra una conducta atrozmente antisocial, de manera que constituyen preceptos mínimos de moral y derecho, que son vindicados ante el tribunal de la razón humana. Un hombre razonable no podría argüír en forma persuasiva que en una sociedad organizada se debería permitir una matanza indiscriminada, que deberían autorizarse el rapto y el pillaje y que el rompimiento de un contrato debería ser estimulado más bien que disuadido. El derecho natural, que forma un ingrediente común en los derechos de los grupos sociales, responde, por lo tanto, al examen ontológico así como al axiológico. Es aprobado por consideraciones tanto empíricas como normativas. Esta conclusión presupone, desde luego, que una sociedad civilizada es preferible a un orden de barbarie y bestialidad; $y$, aunque esto es una cuestión de finalidades últimas, que no puede someterse a comprobación directa y matemática, el juicio de valor implícito

13 Aristóteles, Ética Nicomaquea, Libro V, vii. 
en la conclusión está, según las palabras de John Stuart Mill, "dentro de la comprensión de la facultad racional", 14 y se presta también a una medida substancial de verificación por la prueba empirica de la opinión general de la humanidad. ${ }^{15}$ Si se acepta la premisa, resulta obvio que los valores incorporados a los componentes universales de los sistemas jurídicos no pueden ser sustituidos por los opuestos a estos valores. De otro modo, la vida humana en sociedad se volveria insoportable.

El segundo argumento contra el ius naturale que será discutido aqui, podría iniciarse con la admisión de que las observaciones anteriores pueden considerarse como correctas. Sin embargo, los sostenedores de este nuevo argumento afirmarian que el uso del término "derecho natural", como una descripción abreviada del enfoque del derecho arriba examinado, carece de sentido y es engañoso. Admitiendo la existencia de patrones jurídicos uniformes en civilizaciones diferentes, se dice, este fenómeno no tiene nada que ver con la naturaleza humana. El punto fue elaborado por Hans Kelsen en un artículo reciente, en el cual aparecen los pasajes siguientes: "Del hecho de que seres humanos vivan siempre y por todas partes bajo un orden que regula su conducta recíproca no se puede sacar la conclusión de que este orden esté arraigado en su naturaleza. Tal orden los obliga a renunciar a la satisfacción de muchos impulsos, especialmente de sus tendencias agresivas, que son tan naturales como sus impulsos cooperativos. Los órdenes sociales están en armonía así como en conflicto con la naturaleza, concebida como la condición fáctica del hombre." 16

Kelsen está incuestionablemente sobre terreno firme cuando asevera que la nauraleza humana es contradictoria, multiforme y en partes irracional. Urgencias instintivas, emociones en niveles inferiores y superiores y elementos racionales existen en los seres humanos en grados variables de intensidad, y estos diferentes strata de la naturaleza humana están a menudo en conflicto los unos con los otros.

Sin embargo, debe negarse enfáticamente que la compuesta y compleja estructura de la personalidad humana haga imposible e inútil derivar los aspectos recurrentes del dominio jurídico a partir de ciertos hechos ontológicos concernientes a la naturaleza del hombre. La doctrina iusnaturalista reconoce que la inmoralidad, la agresión y los impulsos antisociales existen

14 Mill, Utilitarianism 7 (ed. Piest, 1957).

15 Este punto fue elaborado en Bodenheimer, "The Province of Jurisprudence", $4^{6}$ Corn. L. Q. $I$ (ig6o).

16 Kelsen, "Die Grundlage der Naturrechtslehre", 13 Oesterr. Ztschr. Oeff. R., $I$, 19-20 (1969). Cf. también Cohen, "Moral Aspects of the Criminal Law", 49 Yale L. J. 987,994 (1940). 
en la realidad natural, pero afirma que la naturaleza de los seres humanos, bajo circunstancias normales, contiene también elementos sociales y racionales, que son utilizados por la institución del derecho con el fin de producir un orden viable para la existencia social. Inclusive Thomas Hobbes, quien sostiene una visión pesimista de la psique humana, que culmina en la convicción de que "todos los hombres en estado de naturaleza tienen un deseo y voluntad de herir", ${ }^{17}$ admitía al mismo tiempo que la naturaleza humana comprende también "pasiones que inclinan. al hombre hacia la paz",18 y que "fácilmente puede juzgarse cuán contrario es para la preservación, sea de la humanidad o de cada hombre en particular, una guerra perpetua".19 Luego concluía que la razón (que es una parte de la naturaleza humana) "sugiere un conveniente Tratado de Paz, sobre cuya base los hombres puedan ser inducidos a la concordia". ${ }^{20}$ Otros filósofos de la tradición iusnaturalista han subrayado los componentes socialmente constructivos de la personalidad humana en forma aún más vigorosa que Hobbes.21

Por lo tanto, parecería correcto afirmar que la doctrina iusnaturalista no trata de deducir la necesidad de ciertas normas sociales de una consideración de la naturaleza humana como un todo, sino que para sus fines aísla ciertos elementos de esta naturaleza que inclinan al hombre hacia una conducta cooperativa, haciendo ast posible una sociedad ordenada y coherente. Al mismo tiempo, la doctrina iusnaturalista admite que hay otros atributos de la naturaleza humana, tales como una insaciable agresividad y una autoafirmación groseramente antisocial, que deben refrenarse hasta el grado necesario para la realización de los fines fundamentales de la organización social.

Esta concepción del iusnaturalismo parecería ser perfectamente compatible con los hallazgos de la ciencia psicológica moderna, y particularmente de la ciencia psicoanalítica. La psicología actual subraya (a veces hasta en forma exagerada) que existe una fuerte dosis de irracionalidad en el modo de ser del hombre. Pero la teoría psicoanalista reconoce también un componente de la personalidad humana, al cual Sigmund Freud ha denominado "super-ego". Es éste un conocimiento de normas inhibitorias que forman parte de la psiqué humana y que está destinado a contender con y dominar al $i d$, o sea, las tendencias y presiones instintivas, conscientes o subconscientes. Freud hace notar que en las primeras fases de la vida humana las funciones del super-ego son efectuadas por una autoridad externa, los padres, que imponen restricciones a los impulsos libidinosos así como los ex-

17 Hobbes, De Cive, Ch. 1. 4. (ed. Lamprecht, 1949).

18 Hobbes, Leviathan, Ch. XIII (Everyman's Libr., ed. 1914).

19 Hobbes, op. cit. supra n. 17., Ch. I. 13.

20 Hobbes, op. cit. supra n. 18 , Ch. XIII.

21 Véase, por ej., Pufendorf, 2 De Jure Naturae et Gentium, Libro I1, Ch. 2. (trad. Oldfather, 1934); Grotius, 2 De Jure Belli ac Pacis, Proleg. 6 (trad. Kelsey, 1925). 
cesivamente egoistas de sus hijos. Cuando el hijo crece y llega a la madurez, este conjunto de normas restrictivas morales se convierte en algo "interiorizado", para utilizar la expresión propia de Freud. La autoridad paternal es sustituida por el super-ego, que en la forma de la conciencia moral "observa, dirige y amenaza después al ego exactamente del mismo modo como antes lo ejecutaron los padres". ${ }^{22}$

Freud no nos dice en detalle cómo se lleva a cabo esta transformación de una autoridad impuesta dentro de mecanismos interiorizados de una autocensura moral; quizás no sabremos nunca la contestación completa. Se han hecho sugestiones en el sentido de que el super-ego se desarrolla mediante una identificación puramente habitual del hijo, con las actitudes y juicios de sus padres. Pero como también estamos muy familiarizados con el fenómeno de la rebelión juvenil contra la autoridad moral de los padres, sería más realista suponer que la persona normal, una vez que alcanza cierto nivel de madurez, selecciona como obligatorias para sí aquellas normas morales y sociales que, en su propia experiencia y juicio, son necesarias para enfrentarse al medio y avanzar en el trato con sus semejantes. Desde luego, debe reconocerse que el ajuste social exigido por el super-ego raramente tiene éxito total, y que las actitudes antisociales sobreviven en cada uno en grados variables. Como ha notado Franz Alexander: "hay un conflicto perpetuo, inclusive en personas normales, entre las desajustadas tendencias instintivas originarias, y la influencia restrictiva del super-ego". ${ }^{23}$

Hay un enlace entre la suposición hecha por la doctrina iusnaturalista de una naturaleza racional del hombre, productora de ciertas formas recurrentes de regulación jurfdica, y el asentimiento interior de la persona humana adulta a las restricciones morales sobre los impulsos instintivos, supuesto por el psicoanálisis moderno. Que las restricciones morales sobre la agresión, que son impuestas al niño por sus padres y más tarde aceptadas por él como necesarias y debidas, se recubren en gran parte con las prohibiciones legales contra homicidio, asalto, robo, rapto, difamación y otras formas de conducta prohibida, es evidente. Por lo tanto puede decirse que la doctrina iusnaturalista y el psicoanálisis están manejando aqué esencialmente la misma materia. Por otra parte, la teoría psicoanalítica parece considerar el código moral como inicialmente impuesto a la persona humana, por una fuerza exterior, los padres, mientras que la doctrina iusnaturalista tiende a encontrar esto profundamente arraigado en la estructura de la personalidad humana. El psicoanálisis no parece haber emprendido un examen que penetre en la relación entre los elementos de mando y aceptación, en la teoria del super-ego. Si se hiciera tal examen, ofrecería casi ciertamente

22 Freud, 12 Gesammelte Schriften, 216 (1934). Véase también Alexander, Fundamentals of Psychoanalysis, 82 (1948).

23 Alexander, op. cit. supra n. 22, pág. 84. 
dos resultados. En primer lugar, se descubriría que el código moral, que restringe los impulsos destructivos, no puede considerarse fundado únicamente en una imposición extraña, sancionada por la intimidación y el miedo al castigo. El proceso mismo de la "interiorización" del código mediante su aceptación por el individuo maduro demuestra que el fenómeno de la conciencia moral y social tiene que estar, en alguna forma, anclado en la estructura psicológica de los seres humanos. El hecho de que todas las sociedades desde los tiempos primitivos hayan desarrollado sistemas éticos, ${ }^{24}$ muestra en forma convincente que hay una necesidad humana, profundamente arraigada, de control normativo de la conducta instintiva e irracional.

El segundo resultado que el examen sugerido puede producir es el descubrimiento basado en la investigación antropológica moderna, ${ }^{25}$ de que muchas de las normas de la conducta social, trasmitidas al niño por los padres como parte del proceso educativo, y absorbidas más tarde por el super-ego, tienen una base axiológica común, no sólo en una comunidad, sino en un nivel mundial. La afirmación de Alexander, de que el código moral (y jurídico), reconocido por el super-ego como obligatorio "se apoya en el ambiente social y varía en medios culturales distintos", ${ }^{26}$ contiene sólo una verdad limitada. En este punto se puede mostrar que la doctrina iusnaturalista está más cerca de un análisis correcto de la realidad social, que algunas versiones de la doctrina psicoanalítica; debe acentuarse, empero, que la noción de una ilimitada diversidad en la práctica moral de ninguna manera es parte necesaria o siquiera importante de la teoría del super-ego. Por otro lado, la teoría psicoanalítica es probablemente correcta al suponer que la incubación de la necesidad moral es en gran medida el producto de un entrenamiento deliberado y de la educación, mientras que un estudio del pensamiento iusnaturalista, al menos en algunas de sus manifestaciones, produce la impresión de que el sentido moral es considerado como algo totalmente autónomo e innato en la personalidad. Si ésta es, o era, la opinión predominante en la doctrina iusnaturalista, entonces este aspecto de la misma necesita revisión y reexposición. Aunque el sentido moral tiene sus raíces en la naturaleza humana (de otra manera la humanidad no habria producido sistemas éticos que muestren muchas semejanzas importantes), no se desarrolla suficientemente sin estímulo desde fuera y sin guía, y requiere de constante atención, cultivo y aliento. Así como la capacidad de aprender y entender, existe el sentido moral en la mayoría de los seres humanos, como potencialidad que ha de ser transformada en realidad mediante dirección educativa, esfuerzo individual y creación de una atmósfera ambiental ade-

24 Linton, "Universal Ethical Principles: an Anthropological View", en Moral Principles of Action, 645, 658 (ed. Anshen, 1952).

25 Para referencias a la bibliografia, véase supra n. 6.

26 Alexander, op. cit., supra n. 22, pág. 82. 
cuada. Pero estas posibles divergencias entre la teoría iusnaturalista y la ciencia psicoanalitica no deberían oscurecer el hecho de que ambos enfoques de la realidad reconocen la existencia, en el ser humano sano, de un sistema de controles sobre el impulso, que forma parte de la personalidad humana después de que ha alcanzado una cierta etapa de desarrollo.

Concluimos que la opinión de Kelsen, quien niega que las normas jurídicas pueden deducirse de la naturaleza, debe ser rechazada. Esa opinión sólo tendria validez, si la doctrina del derecho natural pretendiera considerar la naturaleza humana total y a menudo contradictoria.

\section{III}

Otra critica que se ha dirigido contra la filosofía del derecho natural gravita alrededor del cargo de que esta filosofía puede producir una intolerancia doctrinaria, un pensamiento monolítico, un gobierno autocrático y otras barreras para el progreso humano. Wolfgang Friedmann, por ejemplo, ha dicho: "Lejos de ver en el renacimiento de las filosofías iusnaturalistas un signo claro del retorno a estándares y valores absolutos, me inclino a pensar que algunos de sus aspectos reflejan la nueva dirección hacia la intolerancia -un rasgo tan angustioso de muchas de nuestras sociedades llamadas democráticas, como también de las que son francamente totalitarias."27 Eugene Gerhart, al dirigir su ataque sobre todo en contra de los enfoques católicos de la filosofía jurídica, ha afirmado: "Como una base para el absolutismo autoritario, ...el derecho natural proporciona un fundamento ideal, una premisa mayor excelente." 28 Robert Gordis, un rabí judío simpatizante en general con el renacimiento del iusnaturalismo en una forma modernizada, formuló la acusación, con respecto a la historia pasada de esta actitud filosófica, de que "raras veces los abogados o defensores prácticos del derecho natural pueden encontrarse en las fronteras del pensamiento ético. Hist $\delta$ ricamente, el iusnaturalismo se ha manifestado mucho más como un factor limitativo y restrictivo en la actividad humana, que como un principio liberador que contribuya al crecimiento y desarrollo". 29 Samuel Shuman afirmó en una obra reciente que "el iusnaturalismo, a pesar de algunos de sus resultados envidiables y de su papel, pragmáticamente justificable, en la elaboración de decisiones políticas, tiende a obtener sus loables resultados sustituyendo la elección individual por la opinión colectiva". También pra clamó la opinión de que trae consigo el peligro de una "disminución de la responsabilidad individual moral y política". 30

27 Friedmann, "Natural Law", Carta al Editor, g1 Can. Bar Review, 1074 (1953).

28 Gerhart, American Liberty and "Natural Luw", 118 (1959).

29 Gordis, The Root and the Branch, 212 (1962).

so Shuman, Legal Positivism, 207 (1963). 
Es indudablemente cierto que las teorías iusnaturalistas pueden ser proyectadas en tal forma que sirvan a muchas causas distintas, y que el iusnaturalismo puede ser utilizado, entre otras cosas, para fomentar filosofías de intolerancia, fanatismo y superioridad racial, según la opinión particular que se adopte de "la naturaleza humana". Tiene que acentuarse, empero, que aquellas teorias iusnaturalistas, que son reconocidas hoy como las manifestaciones más representativas $e$ influyentes de este enfoque, no pueden ser sometidas a la crítica indicada por las citas anteriores. Las doctrinas de los estoicos romanos, por ejemplo, subrayaban la igualdad de los hombres en una sociedad política que distaba mucho de ser igualitaria. Sus enseñanzas, junto con otras causas, han ayudado a mejorar la condición de los esclavos, a conceder a las mujeres un grado mayor de igualdad en el orden social, y a incrementar los derechos de los hijos. La perspectiva antinacionalista y cosmopolita de los pensadores estoicos, junto con la idea de igualdad de las razas y pueblos, tuvo cierta participación en el otorgamiento de los derechos de ciudadanía a los habitantes de las provincias romanas, que antes habían ocupado el status de meros súbditos del Imperio Romano.31

Mientras Santo Tomás de Aquino tendía en sus escritos políticos a dar apoyo eficaz a las instituciones políticas y sociales de la sociedad feudal de su época, su teoría del derecho natural, que era una piedra angular de su filosofía jurídica, carecía por completo de todo elemento de intolerancia y glorificación del statu quo. Su catálogo de principios básicos del derecho natural incluía el derecho de la autoconservación, el instinto sexual, la educación de la propia descendencia, la búsqueda del conocimiento, el deseo de vivir en sociedad y el propósito de evitar hacer daño a otros; con respecto a la utilización concreta de estos principios en diferentes épocas y diferentes sociedades, Santo Tomás adoptó una actitud relativista. ${ }^{32}$ Esta amplia generalidad de los preceptos tomistas sobre el derecho natural, combinados con la flexibilidad en su aplicación, movió a Jerome Frank, un pensador no-católico y juez tolerante, a decir que no podía comprender "cómo algún hombre razonable puede hoy negarse a adoptar como base de la civilización moderna los principios fundamentales del derecho natural relativos a la conducta humana, como fueron formulados por Tomás de Aquino". 33

La gran mayoría de las doctrinas iusnaturalistas de los siglos xvII y xviII tendían a favorecer los ideales de libertad y tolerancia más bien que los contrarios a estos valores. Grocio, Pufendorf, Wolff y Thomasio, aunque permanecieron en la corriente principal de su época al defender el tipo de monarquía absoluta característica de la "edad de la ilustración",

31 Para una relación del impacto de la doctrina estoica sobre la legislación romana, véase Bodenheimer, "Jurisprudence: The Philosophy and Method of the Law", págs. 1620 (1962).

32 Santo Tomás de Aquino, Summa Theologica, Q. 94, art. 2.

33 Frank, Law and the Modern Mind, prefacio a la edición de 1949. 
proclamaron códigos de derecho natural decididamente humanitarios en su perspectiva. Thomasio, por ejemplo, fue el primero entre los juristas que luchó contra los procesos de brujerías, y también rechazó, enérgicamente, el uso de la tortura. ${ }^{34}$ Hobbes, aunque favoreció el establecimiento de un gobierno fuerte, procuró sujetar a los gobernantes de Leviatán a un conjunto de preceptos morales, que colocan a este autor muy lejos de los protagonistas de la moderna dominación totalitaria. Rousseau puso algunos de los fundamentos para la ideología de la democracia moderna. Afirmar que Locke y Jefferson fueron defensores de una teoría iusnaturalista, caracterizada por la intolerancia, sería el colmo de lo absurdo.

La restauración del pensamiento iusnaturalista después de la segunda Guerra Mundial se dirigió sobre todo en contra de las prácticas inhumanas de ciertos gobiernos totalitarios. Seria difícil encontrar, entre las teorías de esta clase que han atraído la atención de los juristas contemporáneos, algunos intentos significativos de legitimar formas nuevas de medievalismo o represión. La filosofía post-bélica de Radbruch, la jurisprudencia iusnaturalista de la Suprema Corte de Alemania Occidental, las ideas de Verdross, y varias versiones del pensamiento jurídico neotomista puede decirse que pertenecen a la tradición occidental del humanismo. La acusación, formulada por Shuman, de que la doctrina iusnaturalista es capaz de disminuir la responsabilidad individual, carece totalmente de base, ya que la mayoría de sus partidarios han afirmado que bajo ciertas circunstancias los hombres tendrían el valor moral de oponerse a las órdenes de los gobernantes que violasen los axiomas más elementales de la decencia humana.

Estos ejemplos bastan para mostrar que un rechazo del iusnaturalismo sobre la base de que es una máscara ideológica para formas monolíticas y retrógradas de gobierno y derecho, carece de fundamento. Los pensadores liberales y humanitarios tienen muchas buenas razones para mirar con preferencia muchas de las versiones históricas más influyentes de la doctrina iusnaturalista. Aunque esta doctrina, como cualquiera otra teoría politica o social, se presta a distorsión y abuso, los peligros que evoca en este respecto son mucho menos evidentes que los riesgos producidos por una filosofía de positivismo jurídico. La doctrina positivista se niega a reconocer cualesquiera limitaciones intrínsecas al poder legislativo, y por lo tanto puede fácilmente proporcionar una justificación ideológica para cualquier sistema político que la fantasía humana pueda concebir. Las impresionantes palabras de Hans Welzer que siguen son una útil advertencia de este peligro: "El Tercer Reich tomó el positivismo jurídico al pie de la letra. Puso en práctica la doctrina positivista de que el Estado - como escribió en 1917 el jurista húngaro Somló- 'puede sancionar cualquier contenido concebible

34 Sobre Thomasius, véase Bloch, Naturrecht und Menschliche Wuerde, págs. 315$353(1961)$. 
para el Derecho, inclusive un contenido absolutamente inmoral'... Las especulaciones intelectuales positivistas, como la sugestión de que la orden de asesinar a todos los niños de ojos azules es válida si procede del titular de la soberanía se convirtieron ahora en una espantosa realidad." 35

\section{IV}

La última objeción a la teoría iusnaturalista que discutiremos en este ensayo es la que fue elaborada por Hans Kelsen en diversos artículos. ${ }^{36}$ La crux de esta objeción es el supuesto de que la doctrina iusnaturalista es insostenible desde un punto de vista científico, ya que se afirma con base en una creencia metafísica imposible de verificar, a saber, la de la existencia de un Dios justo. Kelsen juzga que las normas son decretadas necesariamente por alguna persona o grupo de personas; se niega a concebir normas que no sean producidas por un acto de "voluntad". Como ninguna "voluntad" es inmanente a la realidad natural como tal, arguye, la fijación de las normas que, de acuerdo con la doctrina iusnaturalista, pueden derivarse de la naturaleza, tiene que ser atribuida necesariamente al creador de la naturaleza, a Dios. El concepto de un Derecho Natural independiente de la voluntad de Dios es para Kelsen una imposibilidad lógica y filosófica.

La tesis de Kelsen no convence enteramente. Versiones importantes del pensamiento iusnaturalista han sido fundadas sobre una base no teísta. Grocio, por ejemplo, intentó mostrar que el derecho natural puede estar basado sea en un fundamento teológico, sea en uno puramente racionalista. Si puede demostrarse que existen formas recurrentes y típicas de regulación jurídica, que están ancladas en algunos rasgos o inclinaciones de la naturaleza humana, un examen de la cuestión de si la naturaleza humana fue o no creada por una divinidad personal dotada de "voluntad", no se impondría necesariamente. La filosofía del derecho natural no afirma que algunas normas sean "establecidas" por la naturaleza o por el Dios de la naturaleza, sino simplemente juzga que hay normas establecidas por los hombres que fluyen de ciertos atributos de los seres humanos. Por esto no es sorprendente descubrir que una gran parte de la discusión que se centra en torno del problema del derecho natural evita enteramente la cuestión teológica.

Sin embargo, hay un núcleo correcto en la tesis de Kelsen que debe ser extraído de la capa circundante de una argumentación que no concluye. La doctrina iusnaturalista afirma que los poderes racionales de la humanidad son suficientemente fuertes para producir (después de un periodo inicial,

35 Welzel, "Naturrecht und Rechtspositivismus", en Naturrecht oder Rechtspositivismus, 322, 323 (Ed. Maihofer, 1962).

36 Kelsen, "The Natural-Law Doctrine before the Tribunal of Science", 2 West. Pol. Q., $4^{81}$ (1949); Kelsen, "Die Grundlage der Naturrechtslehre", ${ }_{3}$ Oesterr. Zstchr. Oeff. R., 1 (1933). 
quizás, de andar a tientas en la oscuridad) en todas las sociedades disposiciones normativas que tienden a dominar el uso indiscriminado de la violencia y deshonestidad, haciendo así posible una vida tolerable en la sociedad. En este análisis de la realidad va implícita una nota optimista, una convicción consciente o subconsciente de que en balance - aun cuando el balance fuera precario - la suma del bien en este mundo excede al volumen del mal. Si uno está seguro, como Sigmund Freud lo estaba en los últimos años de su vida, de que hay un eterno empate entre el bien y el mal, de manera que las fuerzas de afirmación y construcción son siempre compensadas y equilibradas por los poderes de la negación y de la destrucción, entonces es difícil creer en la existencia de un derecho natural que garantice un mínimo de racionalidad en las relaciones entre los hombres y que reprima las manifestaciones más ultrajantes de la conducta antisocial. Tal derecho natural quedaría reducido a la impotencia, de manera que no podría constituir una base positiva para los sistemas de justicia, si la razón, a pesar de caídas transitorias y eclipses parciales, no prevaleciese en último análisis sobre la sinrazón. Esta creencia, aunque tiene cierta relación con la creencia medieval de que en la eterna y oscilante batalla entre Dios y el demonio el primero emergerá como vencedor final, no necesariamente tiene un carácter teológico. Pero como esta convicción no puede ser probada en forma concluyente por una evidencia que fuera aceptable para un especialista de las ciencias naturales, o en un tribunal de justicia, tiene entonces una base metafísica, si bien un estudio atento de la historia humana y de la conducta humana media en la sociedad, puede establecerla como verdad probable.

La doctrina iusnaturalista, desde luego, no ha pasado por alto la frecuencia en la historia de las guerras destructivas, en que fueron suspendidas las reglas normales que gobiernan las relaciones mutuas entre los hombres. Hasta épocas relativamente recientes, empero, las guerras sólo afectaban, en general, a pequeños sectores de la población, y los poderes de devastación de las armas que se emplearon fueron limitados. Puede ser muy difícil conservar toda fe en el predominio final de la razón sobre la sinrazón, creencia subyacente bajo la doctrina iusnaturalista, en una época en que el mundo está amenazado por la extinción atómica. Pero aun en el caso de que sucediera esta eventualidad improbable, de que el mundo fuera borrado como consecuencia de una total recalda de los gobiernos y de los hombres en la irracionalidad y la destructividad, un estudioso de historia, entre los últimos sobrevivientes, podría aun concluir que el experimento humano, mientras perdurase, valía la pena y que a pesar del sufrimiento, de la enfermedad y de la muerte, la mayoría de los hombres no consideraron sus vidas como malgastadas, ni la no-existencia como preferible a la existencia. 